\title{
Influence of Electrolyte Temperature on Morphology and Properties of Composite Anodic Film on Titanium Alloy Ti-10V-2Fe-3Al
}

\author{
Yulong $W u^{1}$, Haisheng $W_{u}{ }^{2}$, Liang $W u{ }^{1,3, *}$, Zhi-Hui Xie ${ }^{4}$, Lei Liu ${ }^{1}$, Xu Dai ${ }^{1}$, Gen Zhang ${ }^{5}$, \\ Wenhui Yao ${ }^{1}$, Yu Li ${ }^{2}$ and Fusheng Pan ${ }^{1,3}$ \\ 1 State Key Laboratory of Mechanical Transmission, College of Materials Science and Engineering, \\ Chongqing University, Chongqing 400044, China; yulongwu@cqu.edu.cn (Y.W.); \\ liulei12580@foxmail.com (L.L.); xudai@cqu.edu.cn (X.D.); yaowh2012@cqu.edu.cn (W.Y.); \\ fspan@cqu.edu.cn (F.P.) \\ 2 Beijing Spacecrafts, China Academy of Space Technology, Beijing 100094, China; whser@163.com (H.W.); \\ liyu5292s@cqu.edu.cn (Y.L.) \\ 3 National Engineering Research Center for Magnesium Alloys, Chongqing University, Chongqing 400044, China \\ 4 Chemical Synthesis and Pollution Control Key Laboratory of Sichuan Province, College of Chemistry and \\ Chemical Engineering, China West Normal University, Nanchong 637002, China; zhxie@cwnu.edu.cn \\ $5 \quad$ Nuclear Power Institute of China, Chengdu 610213, China; yxyszhang@foxmail.com \\ * Correspondence: wuliang@cqu.edu.cn
}

Received: 20 October 2020; Accepted: 15 November 2020; Published: 19 November 2020

\begin{abstract}
In this study, we introduced a novel environmentally-friendly electrolyte consisting of polytetrafluoroethylene (PTFE) nanoparticles and malic acid solution to fabricate composite anodic film on Ti-10V-2Fe-3Al alloy at different electrolyte temperatures. The morphology revealed that the PTFE nanoparticles were successfully incorporated into composite anodic films and embedded preferentially in the pores and cracks. Their performances (wear, corrosion and hydrophobicity) were evaluated via electrochemical tests, ball on disc tests, and a contact angle (CA) meter. Compared to the substrate of titanium alloy Ti-10V-2Fe-3Al, the composite anodic films exhibited the low wear rates, high corrosion resistance and good hydrophobicity. However, the microstructure and morphology of the films were affected by the electrolyte temperature. As a result, their performances were changed greatly as a function of the temperature and the film fabricated at $20^{\circ} \mathrm{C}$ exhibited better performances $\left(\mathrm{CA}=131.95, i_{\text {corr }}=6.75 \times 10^{-8} \mathrm{~A} \cdot \mathrm{cm}^{-2}\right.$, friction coefficient $\left.=0.14\right)$ than those at other electrolyte temperatures. In addition, the corresponding lubrication mechanism of the composite anodic films was discussed.
\end{abstract}

Keywords: Ti-10V-2Fe-3Al; malic acid; electrolyte temperature; composite anodic film; wear resistance; PTFE nanoparticles

\section{Introduction}

Titanium (Ti) and its alloys, possessing good corrosion resistance, high strength-to-weight ratio, good fracture toughness, and high melting point, have been widely used in aerospace-related fields including high-speed propellers, compressor blades, aeromotors etc. [1-4]. However, the $\beta$ titanium alloy Ti-10V-2Fe-3Al, as high-end aerospace corrosion resistant parts, are often exposed to corrosive atmospheric environments or the highly-corrosive marine environments in service [5]. Moreover, their unstable friction coefficient and poor wear properties have limited their wider applications [6,7]. For example, it is easy for erosion wear and failure to occur when dust is inhaled into the engine for titanium alloy compressor blades [8,9]. Consequently, in order to improve 
the corrosion and wear resistance of titanium alloys, a number of surface treatment methods have been studied, including anodization, micro-arc oxidation, laser beam treatments, plasma spray treatments, electroplating, plasma immersion implantation, and so on [10-12]. Among these methods, the anodization is low-cost, simply-operated, and with low energy consumption [13,14]. Additionally, the film fabricated via anodization exhibited excellent corrosion resistance, good biocompatibility, and excellent photo-catalysis [15-17].

In recent years, composite anodic films containing nanoparticles have been studied widely on light metal alloys. Results showed that the application of composite anodic film obviously improved their wear resistance and the anticorrosion ability. For example, adding the hard nanoparticles of $\mathrm{Al}_{2} \mathrm{O}_{3}$ into the $\mathrm{Mg}$-Al layered double hydroxides (LDHs) nanosheets improved the corrosion and wear resistance of the AZ31 alloy as explained by Wu et al. [18]. In their study, the nanoparticles of $\mathrm{Al}_{2} \mathrm{O}_{3}$ can roll between $\mathrm{Mg}$-Al LDHs nanosheets. Li et al. formed the composite film including $\mathrm{SiC}$ nanoparticles on Ti6Al4V alloy by anodization, which also exhibited good anti-wear properties [19]. Hard nanoparticles can change the friction form from sliding to rolling during the friction process, and thereby decrease the friction coefficient and the wear rate [20]. Aliofkhazraei et al. by further adding two kind of hard nanoparticles in composite anodic films proved that $\mathrm{Si}_{3} \mathrm{~N}_{4}$ and $\mathrm{Al}_{2} \mathrm{O}_{3}$ have a synergistic effect and can effectively reduce the wear rate of titanium alloy [21]. By contrast the other kind of nanoparticles are soft nanoparticles that have a self-lubricating effect in coating. Wu et al. and Liu et al. [22,23] fabricated PTFE/Carbon fiber and hybrid PTFE/Kevlar fabric self-lubricating composite coatings, respectively, and both coatings present good hydrophobicity and wear properties owing to the self-lubricating effect of PTFE nanoparticles. Self-lubricating polymers, especially for PTFE, exhibit high bond energy and thus have good hydrophobicity in addition to providing lubrication [24].

Furthermore, commercial electrolytes used for composite anodizing of titanium alloys generally contain strong acid, such as hydrofluoric acid, chromic acid, sulfuric acid and phosphoric acid, which are harmful to the environment and humans $[25,26]$. In addition, such common electrolytes always cause intense hydrogen evolution, resulting in the occurrence of hydrogen embrittlement of titanium alloys $[27,28]$. So, it is urgent to develop a relatively mild and green electrolyte. Malic acid is an environmentally-friendly weak acid with good conductivity and complexing action [29]. In addition, PTFE nanoparticles possess lubricity as well as a hydrophobic property, which can realize composite anodizing by adding them to the electrolyte directly [5]. Therefore, PTFE-containing malic acid was introduced to develop as an electrolyte for the Ti anodization. However, different electrolytes are often matched by their corresponding anodizing temperatures [30]. For example, the traditional sulfuric and phosphoric acids are usually used in ice baths with high energy consumption. Moreover, the distribution of nanoparticles and the performances of the films were also affected by electrolyte temperature. Therefore, the influence of the PTFE malic acid electrolyte temperature on the properties of the composite anodic films is further worthy of being clarified.

In this work, the malic acid solution with PTFE nanoparticles in suspension is developed as a new kind of anodizing electrolyte, aiming to fabricate composite anodic films and improve the wear and corrosion of titanium alloy Ti-10V-2Fe-3Al. The effects of electrolyte temperature on the morphology, structure, composition, corrosion and wear resistance properties of the composite anodic films were investigated. Furthermore, the corresponding lubrication mechanisms of the composite anodic films fabricated at different electrolyte temperatures were elucidated.

\section{Experimental}

\subsection{Materials and Preparation}

Commercial forged titanium alloy Ti-10V-2Fe-3Al (with chemical nominal composition shown in Table 1) was cut into plate samples $(20 \mathrm{~mm} \times 20 \mathrm{~mm} \times 5 \mathrm{~mm})$ for characterization and performance tests. Moreover, PTFE particles (Tianjin Letai Chemical Co. LTD., Tianjin, China) were emulsified with 
a concentration of 60 wt.\%. Malic acid $\left(\mathrm{C}_{4} \mathrm{H}_{6} \mathrm{O}_{5}, \mathrm{AR}\right)$ was purchased from Chengdu Kelong Chemical Reagent Factory, China. Deionized water was used as the solvent in this work.

Table 1. The nominal chemical composition of Ti-10V-2Fe-3Al (wt.\%).

\begin{tabular}{cccccc}
\hline $\mathbf{V}$ & $\mathbf{F e}$ & $\mathbf{A l}$ & $\mathbf{C}$ & $\mathbf{O}$ & $\mathbf{T i}$ \\
\hline 10.000 & 2.100 & 3.100 & $<0.050$ & $<0.010$ & balance \\
\hline
\end{tabular}

Prior to treatment, all samples were mechanically ground with silicon carbide paper from 150 to 3000 grit, followed by drying in air. The whole preparation process is illustrated in Figure 1. At the beginning, the prepared samples were ultrasonically cleaned in acetone, degreased in a mix solution of $\mathrm{NaOH}(40 \mathrm{~g} / \mathrm{L}), \mathrm{Na}_{2} \mathrm{SiO}_{3}(25 \mathrm{~g} / \mathrm{L}), \mathrm{Na}_{2} \mathrm{CO}_{3}(25 \mathrm{~g} / \mathrm{L})$ and $\mathrm{Na}_{3} \mathrm{PO}_{4}(40 \mathrm{~g} / \mathrm{L})$ for $20 \mathrm{~min}$ at $50{ }^{\circ} \mathrm{C}$, and activated in a solution of $\mathrm{NaOH}(10 \mathrm{~g} / \mathrm{L})$ and $\mathrm{H}_{2} \mathrm{O}_{2}(50 \mathrm{~mL} / \mathrm{L})$ for $15 \mathrm{~min}$ at $40{ }^{\circ} \mathrm{C}$ [31]. After each step, all samples were rinsed in deionized water and dried in warm air. The anodizing process was conducted using a pulse galvanostatic power supply (PGPS, WMY-IV, 708th Research Institute of Astronautics, Beijing, China), whose pulse was a unidirectional square wave shown in the upper right corner of Figure 1. A $1 \mathrm{Cr} 18 \mathrm{Ni}$ Ti stainless steel plate was employed as the cathode. The surface area ratio of the cathode to the anode was more than 3:1. The electrolyte was composed of $15 \mathrm{~g} / \mathrm{L}$ malic acid and $10 \mathrm{~mL} / \mathrm{L}$ PTFE (about $100 \mathrm{~nm}$ in diameter). The anodizing process was carried out at a constant current density of $8 \mathrm{~A} / \mathrm{dm}^{2}$. The frequency, duty ratio, and anodizing time were $1.3 \mathrm{~Hz}, 20 \%$ and $60 \mathrm{~min}$, respectively. The electrolyte was stirred and the temperature was controlled using a thermostatic water bath (DF-101S) with the corresponding condensing system. Electrolyte temperature was kept at 10, 20, 30, 40 and $50{ }^{\circ} \mathrm{C}$ during anodizing, respectively. After anodizing, each sample was rinsed with deionized water and dried in air.

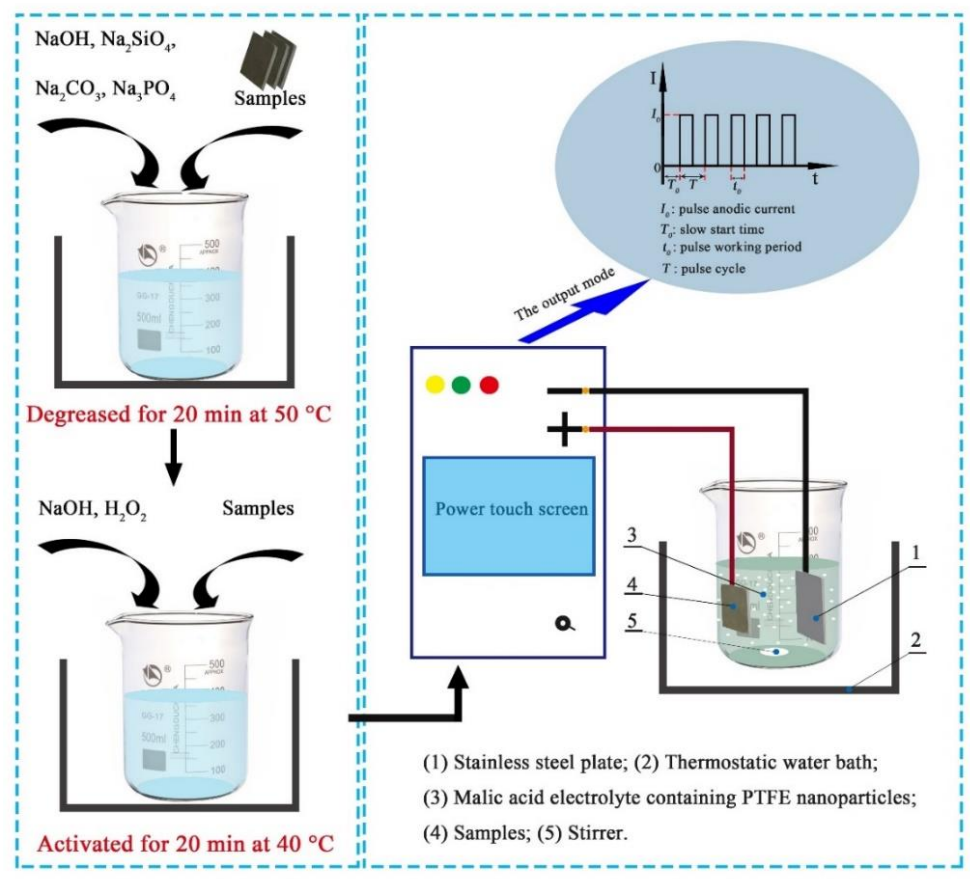

Figure 1. Fabrication illustration of composite anodic films.

\subsection{Characterization}

The surface and cross-sectional morphologies of composite anodic films were evaluated using a field emission scanning electron microscope (FE-SEM, XL30S, FEI, Pleasanton, CA, USA) equipped with an energy dispersive spectroscopy analyzer (EDS, link ISIS, Oxford, UK). The roughness of the coatings was examined using an atomic force microscope (AFM, Dimension icon, Veeco, 
Santa Barbara, CA, USA). The water contact angle (CA) was assessed with a contact angle meter (SDC-100, Ding Sheng, Shanghai, China) on four different positions for each sample. The crystal structure was examined using a Raman spectroscopy (Yvon Jobin Horiba-HR 800, He-Ne laser without filter, $650 \mathrm{~nm}$ ). Potentiodynamic polarization curves and electrochemical impedance spectra (EIS) were measured at room temperature in a cell with $3.5 \mathrm{wt} . \% \mathrm{NaCl}$ solution using an electrochemical workstation (Princeton Parstat 4000A, Nashville, TN, USA) equipped with a classical three-electrode system. The system was used with the sample as a working electrode with an exposed area of $1 \mathrm{~cm}^{2}$, a saturated calomel electrode (SCE) as the reference electrode, and a platinum plate as the counter electrode. Polarization curves of all samples immersed in $3.5 \mathrm{wt} . \% \mathrm{NaCl}$ solution for $30 \mathrm{~min}$ were obtained by automatically sweeping the electrode potential from -0.8 to $0.8 \mathrm{~V}$ regarding the open circuit potential $(\mathrm{OCP})$ at a sweep rate of $2 \mathrm{mV} \cdot \mathrm{s}^{-1}$. The impedance measurements were obtained using a 10-mV root-mean-square (rms) sinusoidal perturbation and performed at OCP from 100 to $0.01 \mathrm{~Hz}$. The experimental impedance plots were fitted to equivalent circuits using the Zsimpwin simulation software. For reproducibility, three parallel samples were tested in each system. Tribological tests were conducted using a ball-on-disc rotating wear tester (HT-2001 POD-1, Tianjin, China) for $30 \mathrm{~min}$ using a normal load of $4 \mathrm{~N}$, a rotation radius of $4 \mathrm{~mm}$, a rotating velocity of $200 \mathrm{rpm}$ under ambient conditions. $\mathrm{A} \mathrm{Si}_{3} \mathrm{~N}_{4}$ ceramic ball with a diameter of $5 \mathrm{~mm}$ and surface roughness of about $0.01 \mu \mathrm{m}$ was applied as the counterpart. The friction coefficient was continuously recorded as a function of sliding time. The morphologies of the wear tracks and the chemical composition were measured using SEM (Tescan VEGA 3 LMH SEM, Prague, Czech Republic), a profilometer (Dektak 150, Veeco, Pleasanton, CA, USA), and EDS, respectively.

\section{Results and Discussion}

\subsection{Characterization of Composite Anodic Films}

\subsubsection{Morphology, Composition and Contact Angle Analysis}

Figure 2 shows the FE-SEM images, their corresponding contact angles (CAs) and EDS spectra of the composite anodic films fabricated at different electrolyte temperatures. Table 2 lists the analysis results of the corresponding EDS points marked in Figure 2. It can be seen from Figure 2a,b that only several loose bumps with a small amount of PTFE nanoparticles were formed on the substrate. This can be attributed to three reasons: (i) the low electrolyte temperature unfits thermodynamic factors [32], (ii) the $\beta$ phase (the second phase in Ti-10V-2Fe-3Al) existing on the samples may become higher at local electrode temperature $[33,34]$ and (iii) composite anodic films first appear on the $\beta$ phase as explained by Li et al. [31]. Figure 2c,e show that the substrate is completely covered with a dense anodic film composed of many bumps and PTFE nanoparticles. Moreover, Figure $2 \mathrm{~d}, \mathrm{f}$ also show PTFE nanoparticles are aggregated preferentially around the cracks or pores, resulting in the effect of self-sealing of the pores. This is because the required bonding energy in the cracks, pores or sidewalls for the PTFE nanoparticles is lower than that on the flat positions [31,35]. It can be seen from Table 2 that the existence of the F element further indicated PTFE nanoparticles were absorbed into the composite anodic films, likely by inert adsorption or reactive adsorption. In addition, it was found that the change of the PTFE content was affected by the electrolyte temperature, with the minimum and maximum content being 4.27 and 48.54 at.\% at 10 and $20^{\circ} \mathrm{C}$, respectively. As a result, the composite anodic film possesses the large CAs value seen in Figure 2 except it is developed at $10^{\circ} \mathrm{C}$. The EDS spectra and their corresponding CAs indicate that electrolyte temperature can affect the content of PTFE particles, which are correlated with the surface hydrophobicity of the films. Unfortunately, the heat from the $\beta$ phase may find it difficult to spread when the electrolyte temperature is more than $30^{\circ} \mathrm{C}[33,34]$. The composite anodic films become more uneven due to the local dissolution caused by overheating in some areas. In addition, the increase in electrolyte temperature always causes a low $\mathrm{pH}$ and accelerates the dissolution of composite anodic films, which has a great influence on the roughness of the films 
as well. Thus, the CAs value declines from 131.95 at $20{ }^{\circ} \mathrm{C}$ to 92.54 at $50{ }^{\circ} \mathrm{C}$ with the increasing electrolyte temperature.

Table 2. The analysis results of corresponding EDS points in Figure 2.

\begin{tabular}{|c|c|c|c|c|c|}
\hline Elements & $\begin{array}{c}10{ }^{\circ} \mathrm{C}(\text { At. } \%) \\
\text { (1) }\end{array}$ & $\begin{array}{c}\left.20{ }^{\circ} \mathrm{C} \text { (At. } \%\right) \\
\text { (2) }\end{array}$ & $\begin{array}{c}30{ }^{\circ} \mathrm{C}(\text { At. } \%) \\
\text { (3) }\end{array}$ & $\begin{array}{c}40{ }^{\circ} \mathrm{C}(\text { At. } \%) \\
\text { (4) }\end{array}$ & $\begin{array}{c}50{ }^{\circ} \mathrm{C}(\text { At. } \%) \\
\text { (5) }\end{array}$ \\
\hline $\mathrm{OK}$ & 47.59 & 19.29 & 9.98 & 40.67 & 10.83 \\
\hline F K & 4.27 & 48.54 & 35.88 & 23.37 & 10.26 \\
\hline $\mathrm{Al} \mathrm{K}$ & 1.27 & 0.42 & 0.49 & 0.72 & 0.91 \\
\hline Ti K & 21.39 & 12.32 & 18.12 & 18.17 & 38.64 \\
\hline V K & 2.16 & 1.64 & 1.81 & 2.20 & 4.13 \\
\hline Fe K & 0.34 & 0.24 & 0.33 & 0.15 & 0.94 \\
\hline
\end{tabular}
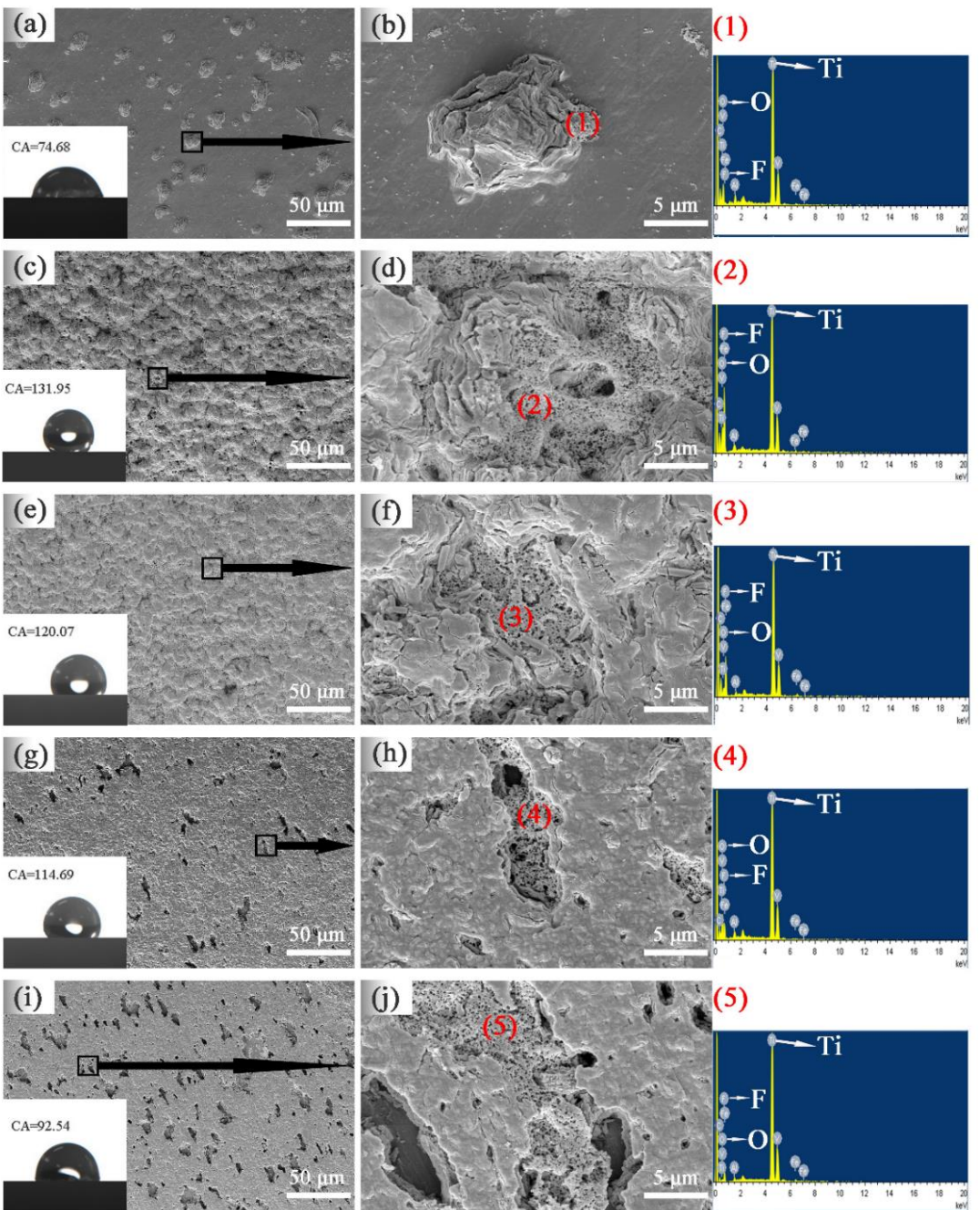

Figure 2. FE-SEM images and the corresponding EDS, contact angles (Cas) of composite anodic films fabricated at different temperatures: (a,b) (1) $10{ }^{\circ} \mathrm{C}$; (c,d) (2) $20{ }^{\circ} \mathrm{C} ;(\mathbf{e}, \mathbf{f})(\mathbf{3}) 30^{\circ} \mathrm{C} ;(\mathbf{g}, \mathbf{h})(\mathbf{4}) 40{ }^{\circ} \mathrm{C} ;(\mathbf{i}, \mathbf{j})$ (5) $50{ }^{\circ} \mathrm{C}$.

Figures 3 and 4 show three-dimensional AFM figures and the corresponding values of root-mean-square (Rrms) roughness and average roughness $(R a)$ obtained from the AFM analysis, respectively. Generally, the rough surface is conducive to the adherence of nanoparticles [31,35]. It can be seen that Figure 3 shows surface roughness increases with the electrolyte temperature from 10 to $20^{\circ} \mathrm{C}$ and is followed by a decrease, which conforms to the adhesion law of PTFE nanoparticles (recall 
Table 2), i.e., larger roughness and higher PTFE nanoparticles content. As suggested by Wenzel's theory, the surface roughness could enhance the hydrophobicity [22]. Thus, surface hydrophobicity of the films was attributed to: (i) the surface roughness and (ii) the PTFE nanoparticles content. Coincidentally, electrolyte temperature affects the distribution of PTFE nanoparticles by affecting the surface roughness. As a result, their synergistic allows the film to have the best hydrophobicity $(\mathrm{CA}=131.95)$ at $20^{\circ} \mathrm{C}$.
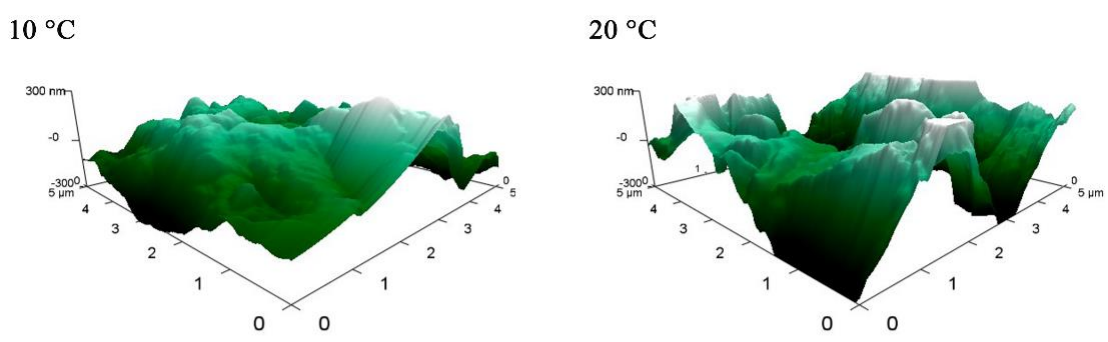

$30^{\circ} \mathrm{C}$
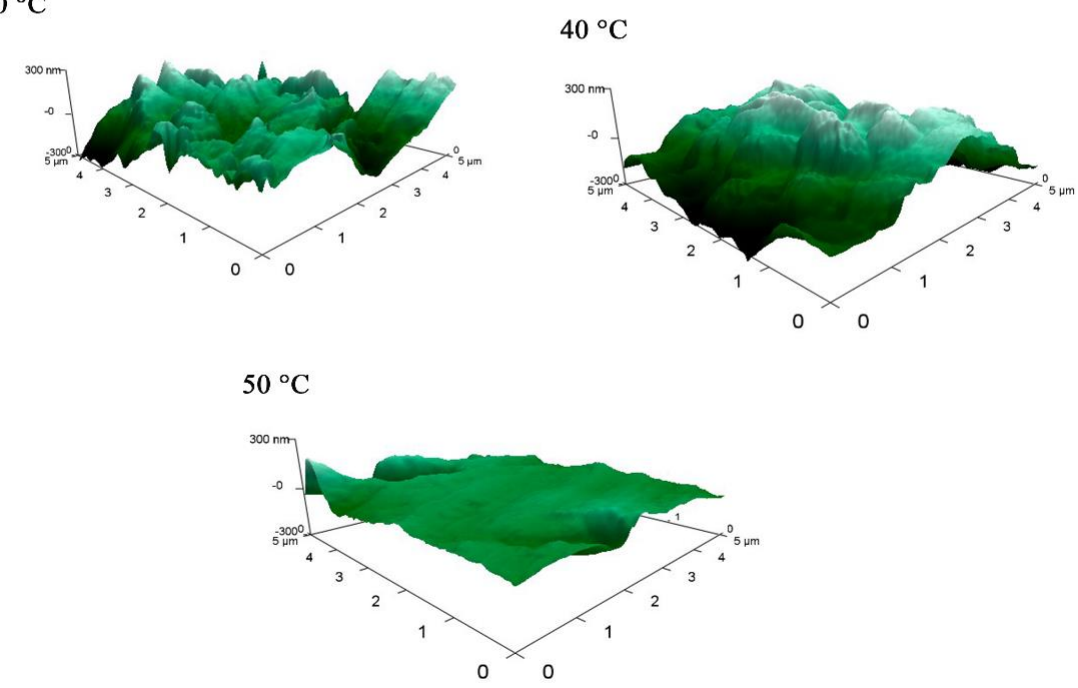

Figure 3. Three-dimensional atomic force microscope (AFM) figures of composite anodic films at different temperatures.

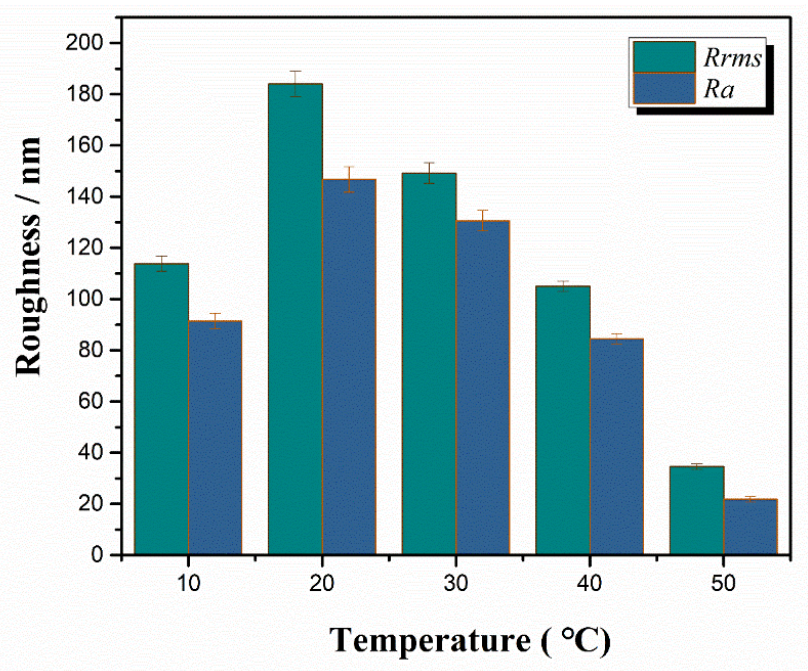

Figure 4. Root-mean-square roughness and average roughness of composite anodic films at different temperatures. 
Figure 5 displays the cross-sectional SEM morphology of composite anodic films fabricated at different electrolyte temperatures. From Figure 5, the cross-sectional SEM morphology of the composite anodic films was dense, which may be related to the PTFE embedded preferentially in the pores and cracks. It is worth mentioning that the adhesion between substrate and the films was also good. The anodic oxidation was a dynamic process of the dissolution and generation of anodic films [10]. High electrolyte temperature will dissolve the composite anodic films; low temperature cannot meet the thermodynamic conditions of film formation. Thus, much higher or much lower electrolyte temperature was not beneficial to the formation of the thick composite anodic films. From Figure 5, we found that the thicknesses of composite anodic films fabricated at 10, 20, 30, 40 and $50^{\circ} \mathrm{C}$ were 1.1 , $19.9,16.8,8.9$ and $4.5 \mu \mathrm{m}$, respectively. The composite anodic film fabricated at $20^{\circ} \mathrm{C}$ was the thickest one without any crack.
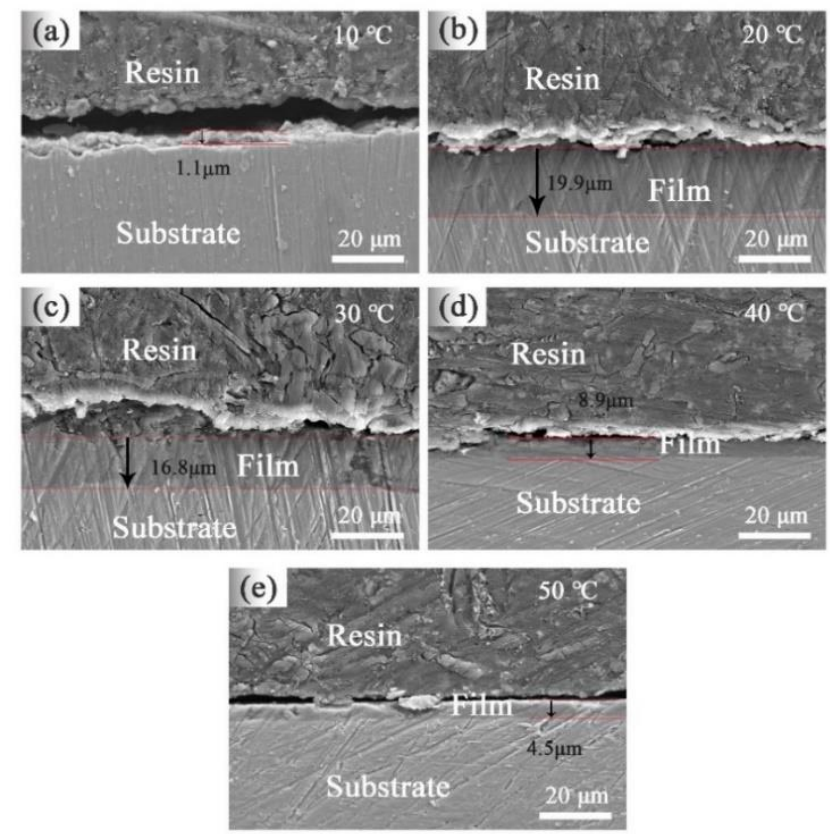

Figure 5. Cross-sectional FE-SEM micrographs of the composite anodic films fabricated at different temperatures. (a) $10{ }^{\circ} \mathrm{C}$, (b) $20^{\circ} \mathrm{C}$, (c) $30{ }^{\circ} \mathrm{C}$, (d) $40{ }^{\circ} \mathrm{C}$, (e) $50{ }^{\circ} \mathrm{C}$.

\subsubsection{Voltage-Time Plots Analysis}

Figure 6 shows the voltage-time curve for composite anodic films fabricated in the electrolyte at different electrolyte temperatures. Usually, the curve can be divided into three stages [36]: (i) the voltage linear increases ( $0 \sim 4 \mathrm{~min})$, (ii) the voltage fluctuates to stability ( $4 \sim 10 \mathrm{~min}$ ) and (iii) the voltage reaches a stable value (10 65 min). This phenomenon is attributed to the change of the resistance during the growth of the film. Obviously, the final voltage increases with the decreasing electrolyte temperature (as shown in Figure 6). Generally, the high voltage is often accompanied by thicker anodic films for a constant electrolyte temperature [37]. Interestingly, in this work, the obtained seem to be not consistent with the usual rule of thumb (recall Figure 5). The reason may be an increased aggressiveness at high electrolyte temperature due to faster kinetics. Moreover, Li et al. [38] concluded that the ionic current increased and electrical resistance decreased with the increasing electrolyte temperature. Therefore, with the increasing ionic current, the $\mathrm{pH}$ value of the electrolyte decreases, the final voltage decreases and the dissolution of the films is accelerated. As a result, the electrolyte temperature is one of the key factors which can affect the thickness of films and the final voltage. 


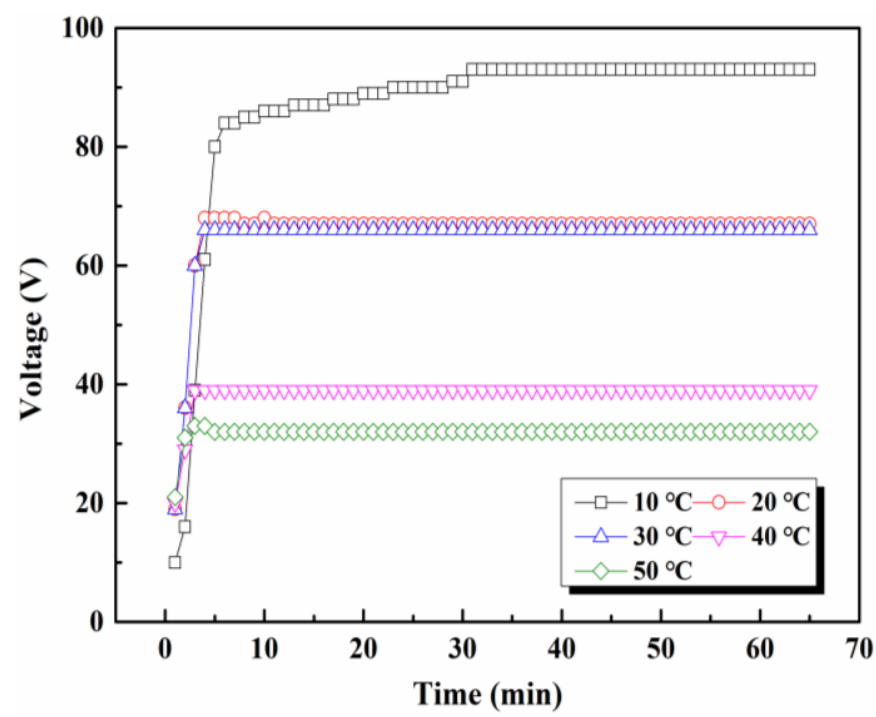

Figure 6. Voltage-time plots of composite anodic films fabricated at different temperatures.

\subsubsection{Structure Analysis}

Figure 7 displays the Raman spectra of the composite anodic films fabricated at different electrolyte temperatures. The intensity of these peaks reaches the maximum at $10{ }^{\circ} \mathrm{C}$ and decreases with the electrolyte temperature. The peak at $158 \mathrm{~cm}^{-1}$ is intense and sharp. It is the characteristic peak of the anatase phase [39]. The peaks at 424 and $608 \mathrm{~cm}^{-1}$ are weaker, and assigned to the Raman active modes of the rutile [40]. The broad weak bands centered at $930 \mathrm{~cm}^{-1}$ are assigned to $\mathrm{V}_{2} \mathrm{O}_{5}$ [41] The intensity of the peaks decreases with the increasing electrolyte temperature. The above results reveal that the composite anodic films fabricated at different electrolyte temperatures possess the same crystal structure. Further, the amounts of the crystalline oxides (anatase and rutile) increase with the electrolyte temperature.

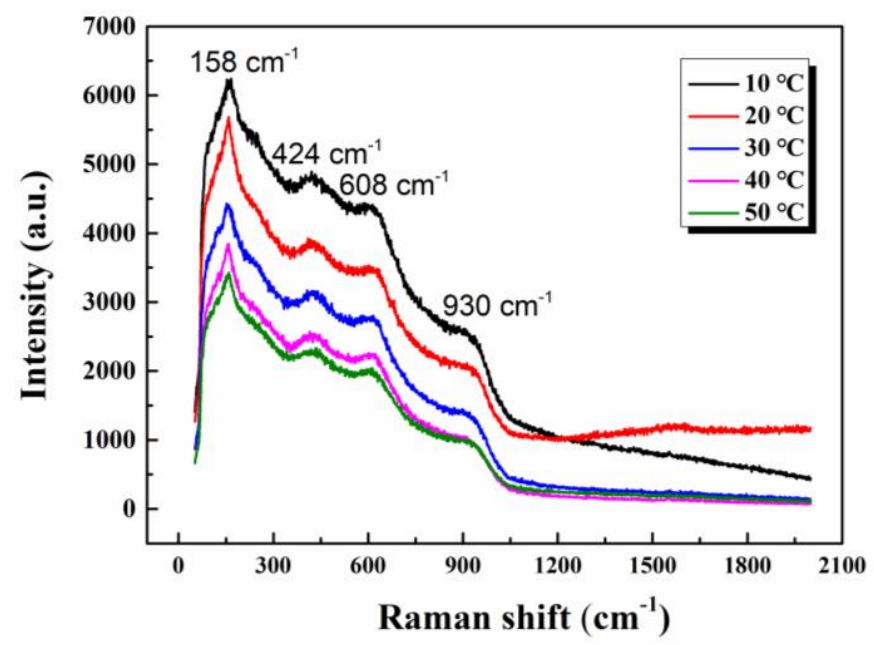

Figure 7. Raman spectra of composite anodic films fabricated at different temperatures.

\subsection{Corrosion Resistance}

Figure 8 shows the potentiodynamic polarization curves of the composite anodic films fabricated at different electrolyte temperatures. The corrosion potential $\left(E_{\text {corr }}\right)$ and corrosion current density $\left(i_{\text {corr }}\right)$ derived from the polarization measurements are listed in Table 3 . The values of the $E_{\text {corr }}$ and $i_{\text {corr }}$ for the substrate are estimated to be $-0.53 \mathrm{~V}_{\mathrm{SCE}}$ and $3.26 \times 10^{-6} \mathrm{~A} \cdot \mathrm{cm}^{-2}$, respectively. The increasing of $E_{\text {corr }}$ of PTFE including composite film could be attributed to the high potential of PTFE and oxide film. 
Moreover, the $i_{\text {corr }}$ value of the composite anodic films decreases by one or two orders of magnitude. In general, the corrosion resistance of the anodizing samples was mainly associated with the thickness, the surface state of anodic oxide films and the composition. The result indicates that the composite anodic film with the best corrosion resistance $\left(E_{\text {corr }}=1.43 \mathrm{~V}\right.$ and $I_{\text {corr }}=6.75 \times 10^{-8} \mathrm{~A} \cdot \mathrm{cm}^{-2}$, sample anodized at $20^{\circ} \mathrm{C}$ ) possesses the highest content of PTFE, the maximum thickness and the best surface hydrophobicity. In addition, the anodic branch of the Tafel curve shows strong passivation, which may be relate to the hydrophobicity and physical barrier of PTFE preventing the immersion of $\mathrm{Cl}^{-}$.

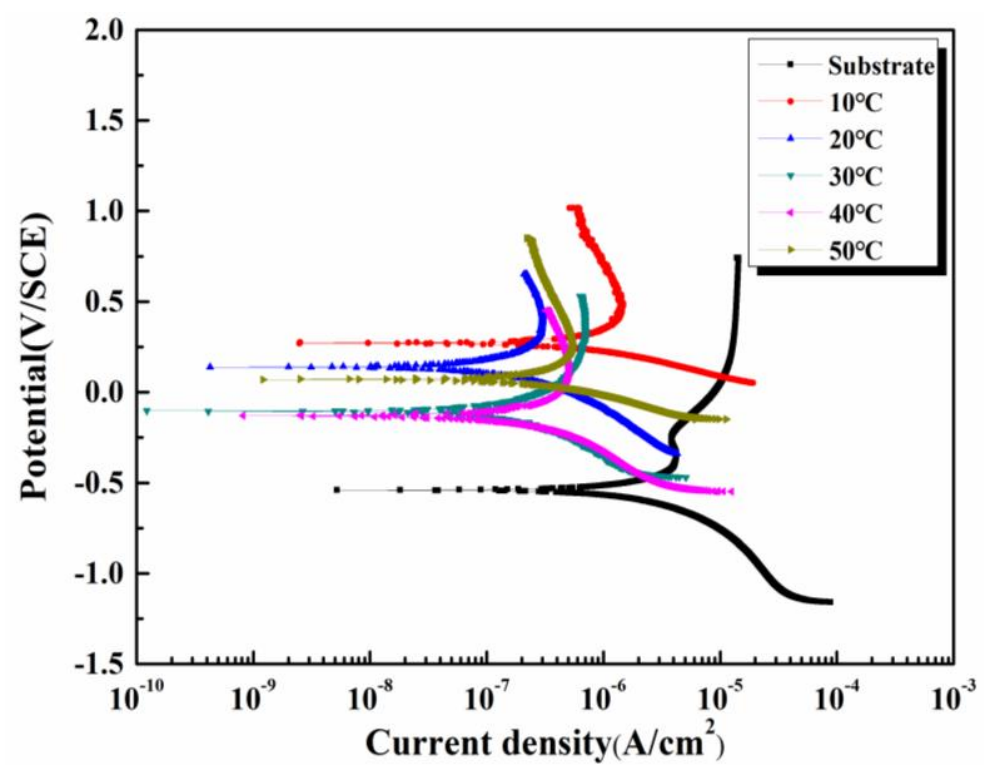

Figure 8. Potentiodynamic polarization curves recorded in $3.5 \mathrm{wt} . \% \mathrm{NaCl}$ solution for the composite anodic film fabricated at different temperatures.

Table 3. Corrosion potential $\left(E_{\text {corr }}\right)$ and corrosion current density $\left(i_{\text {corr }}\right)$.

\begin{tabular}{ccc}
\hline Samples & $\boldsymbol{E}_{\text {corr }}(\mathrm{V} / \mathrm{SCE})$ & $\boldsymbol{i}_{\text {corr }}\left(\mathbf{A} \cdot \mathbf{c m}^{-2}\right)$ \\
\hline Substrate & -0.53 & $3.26 \times 10^{-6}$ \\
$10^{\circ} \mathrm{C}$ & 0.27 & $5.98 \times 10^{-7}$ \\
$20^{\circ} \mathrm{C}$ & 0.14 & $6.75 \times 10^{-8}$ \\
$30^{\circ} \mathrm{C}$ & -0.09 & $1.01 \times 10^{-7}$ \\
$40^{\circ} \mathrm{C}$ & -0.12 & $1.53 \times 10^{-7}$ \\
$50^{\circ} \mathrm{C}$ & 0.07 & $2.51 \times 10^{-7}$ \\
\hline
\end{tabular}

To conduct further study, electrochemical impedance spectroscopy (EIS) was implemented on the samples in $3.5 \mathrm{wt} . \% \mathrm{NaCl}$ solution. The results are shown in Figure 9a,b. The impedance value at lower frequency corresponds to the impedance of the composite films [42], and its magnitude reflects the corrosion ability of the samples. Compared with the substrate sample, the $|\mathrm{Z}|$ value at $10 \mathrm{mHz}$ of the composite anodic films is significantly improved by about one or two orders of magnitude, which is attributed to the anticorrosion ability of the films. In addition, the low frequency region $|Z|$ values are changed with electrolyte temperatures, indicating that the electrolyte temperature has a great influence on $|Z|$ value and corrosion resistance of samples. This is consistent with the results of potentiodynamic polarization curves.

The software (Zsimpwin) is employed to fit and analyze the measured EIS data. The model $R_{\text {sol }}$ $\left(R_{\text {out }} Q_{\text {out }}\left(R_{\text {inn }} Q_{\text {inn }}\right)\right)$ is proposed [43] as shown in Figure 9c, where the $R_{\text {sol }}$ is the solution resistance, the $R_{\text {out }}$ is the resistance of the outer layer of composite anodic films, the $R_{\text {inn }}$ is the resistance of the inner layer of composite anodic films, which is related to the electric charge transfer. The $Q$ is the constant phase elements, replacing the capacitances to demonstrate the non-ideal capacitive behavior of films. 
In particular, $Q_{o u t}, n_{\text {out }}, Q_{i n n}$ and $n_{\text {inn }}$ describe constant phase elements of the outer layer and inner layer, respectively. The fitting quality is evaluated by the value of $\chi^{2}$. Generally, a higher $R_{i n n}$ value implies a lower dissolution rate and a higher anticorrosion ability. As shown in Table 4, the highest $R_{i n n}$ value (approximately $6.15 \times 10^{5} \Omega \cdot \mathrm{cm}^{2}$ ) is the composite anodic films fabricated at $20^{\circ} \mathrm{C}$, indicating the good physical barrier effect of films. Why is the highest $R_{\text {out }}$ at $20^{\circ} \mathrm{C}$ ? The reason may be related to the most PTFE particles (see Table 2) and its best hydrophobicity, which can block the attack of $\mathrm{Cl}^{-}$effectively. Moreover, the $R_{i n n}$ value at $10^{\circ} \mathrm{C}$ is smaller than the substrate, which can be attributed to the incomplete composite anodic film accelerating the corrosion of substrate. This corrosion can be attributed to galvanic corrosion due to the large $E_{\text {corr }}$ (see Figure 8) difference between the composite anodic films and the substrate. The change in $R_{i n n}$ is basically the change in the impedance of the composite anodic film. So, the impedance of the composite anodic film initially increases with electrolyte temperature until it reaches a maximum at $20^{\circ} \mathrm{C}$ and then decreases.

Table 4. Fitted parameters for the electrochemical impedance spectroscopy (EIS) spectrum depicted in Figure 9.

\begin{tabular}{ccccccccc}
\hline Parameter & $\mathbf{R}_{\text {sol }}\left(\boldsymbol{\Omega} \cdot \mathbf{c m}^{\mathbf{2}}\right)$ & $\mathbf{Q}_{\text {out }}\left(\mathbf{S ~ s}^{\mathbf{n}} \cdot \mathbf{c m}^{-\mathbf{2}}\right)$ & $\mathbf{n}_{\text {out }}$ & $\mathbf{R}_{\text {out }}\left(\boldsymbol{\Omega} \cdot \mathbf{c m}^{2}\right)$ & $\mathbf{Q}_{\text {inn }}\left(\mathbf{S ~ s} \mathbf{n}^{\mathbf{n}} \mathbf{c m}^{-2}\right)$ & $\mathbf{n}_{\text {inn }}$ & $\mathbf{R}_{\text {inn }}\left(\boldsymbol{\Omega} \cdot \mathbf{c m}^{\mathbf{2}}\right)$ & $\boldsymbol{X}^{\mathbf{2}}$ \\
\hline Substrate & 14.64 & $5.44 \times 10^{-5}$ & 0.972 & $7.45 \times 10^{4}$ & $6.03 \times 10^{-5}$ & 0.754 & $2.51 \times 10^{3}$ & $4.51 \times 10^{-3}$ \\
$10^{\circ} \mathrm{C}$ & 12.23 & $3.32 \times 10^{-5}$ & 0.300 & $1.72 \times 10^{7}$ & $3.75 \times 10^{-6}$ & 0.628 & $9.55 \times 10^{2}$ & $7.53 \times 10^{-4}$ \\
$20^{\circ} \mathrm{C}$ & 10.06 & $1.64 \times 10^{-9}$ & 0.911 & $1.54 \times 10^{12}$ & $5.71 \times 10^{-7}$ & 0.274 & $6.15 \times 10^{5}$ & $9.21 \times 10^{-3}$ \\
$30^{\circ} \mathrm{C}$ & 15.65 & $5.75 \times 10^{-9}$ & 0.908 & $1.53 \times 10^{8}$ & $1.81 \times 10^{-6}$ & 0.317 & $4.29 \times 10^{4}$ & $2.78 \times 10^{-3}$ \\
$40^{\circ} \mathrm{C}$ & 11.07 & $1.47 \times 10^{-8}$ & 0.814 & $2.37 \times 10^{6}$ & $2.15 \times 10^{-6}$ & 0.191 & $8.77 \times 10^{3}$ & $4.20 \times 10^{-3}$ \\
$50{ }^{\circ} \mathrm{C}$ & 15.36 & $1.73 \times 10^{-6}$ & 0.719 & $1.76 \times 10^{6}$ & $1.04 \times 10^{-5}$ & 0.293 & $1.73 \times 10^{3}$ & $1.04 \times 10^{-3}$ \\
\hline
\end{tabular}

(a)

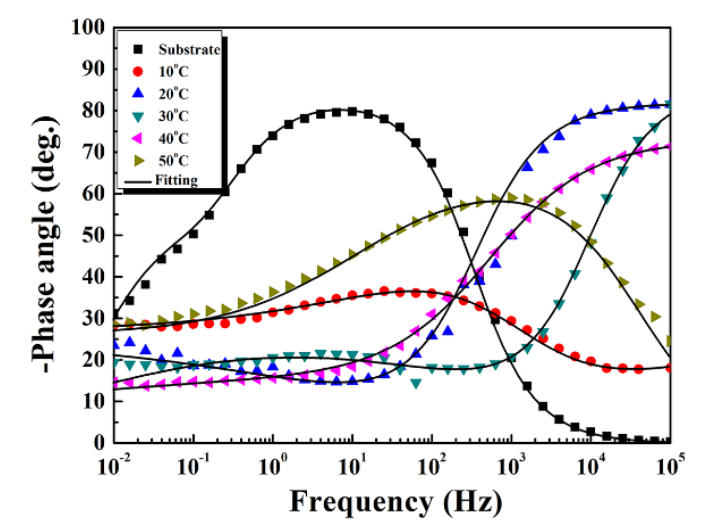

(b)

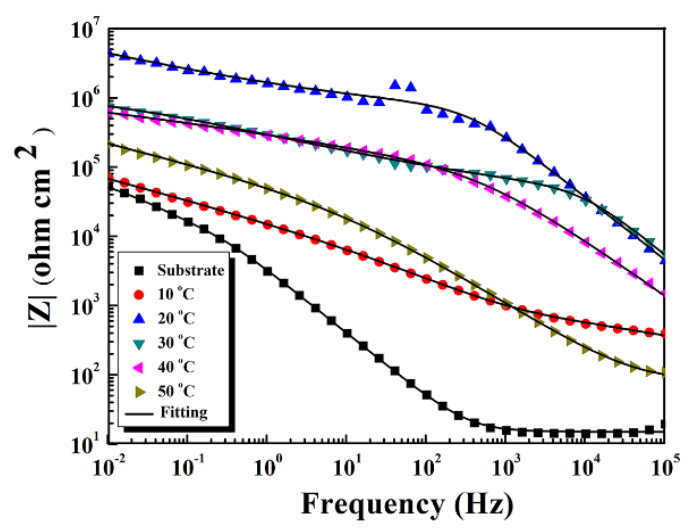

(c)

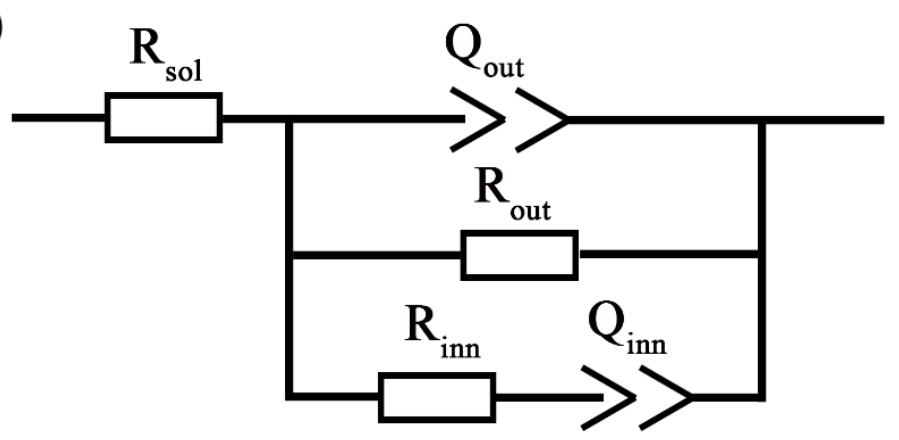

Figure 9. (a,b) are EIS plots of composite anodic films fabricated at different temperatures; (c) equivalent circuits used to fit EIS plots. 


\subsection{Tribological Properties}

Figure 10 depicts the friction coefficient of the composite anodic films fabricated at different electrolyte temperatures. The friction coefficient of the composite anodic film fabricated at $10{ }^{\circ} \mathrm{C}$ increases rapidly to 0.53 at the beginning of the wear process and then decreases to about 0.4 , and then remains stable. Furthermore, the friction coefficient of the Ti-10V-2Fe-3Al alloy substrate is about 0.4 [20]. Therefore, the thin composite anodic film fabricated at $10^{\circ} \mathrm{C}$ has been worn out at the initial time. As shown in Figure 10, the composite anodic film fabricated at $50^{\circ} \mathrm{C}$ is also worn out at the point of $300 \mathrm{~s}$. The friction coefficient of the composite anodic film fabricated at $40{ }^{\circ} \mathrm{C}$ increases with the increasing time and then remains stable at about 0.6. The composite anodic film fabricated $40{ }^{\circ} \mathrm{C}$ is not worn out, but the PTFE nanoparticles are almost used up during the wear test (see the following Table 5). However, the friction coefficient of the composite anodic film fabricated at $20^{\circ} \mathrm{C}$ is about 0.14 and remained stable during the wear test. This may be attributed to the lubricating layer composed of debris and lots of PTEF nanoparticles, which act as the lubricant to reduce the frictional resistance during sliding [10]. The friction coefficient of the composite anodic film fabricated at $30^{\circ} \mathrm{C}$ is about 0.23 , which was larger than that of the film fabricated at $20^{\circ} \mathrm{C}$. This may be related to the content of PTFE nanoparticles on the surface of composite anodic films. The results confirmed that the increasing content of PTFE nanoparticles is beneficial to the formation of the lubrication layer and decreases the friction coefficient. A large amount of debris between the contact areas can provide lubrication [20].

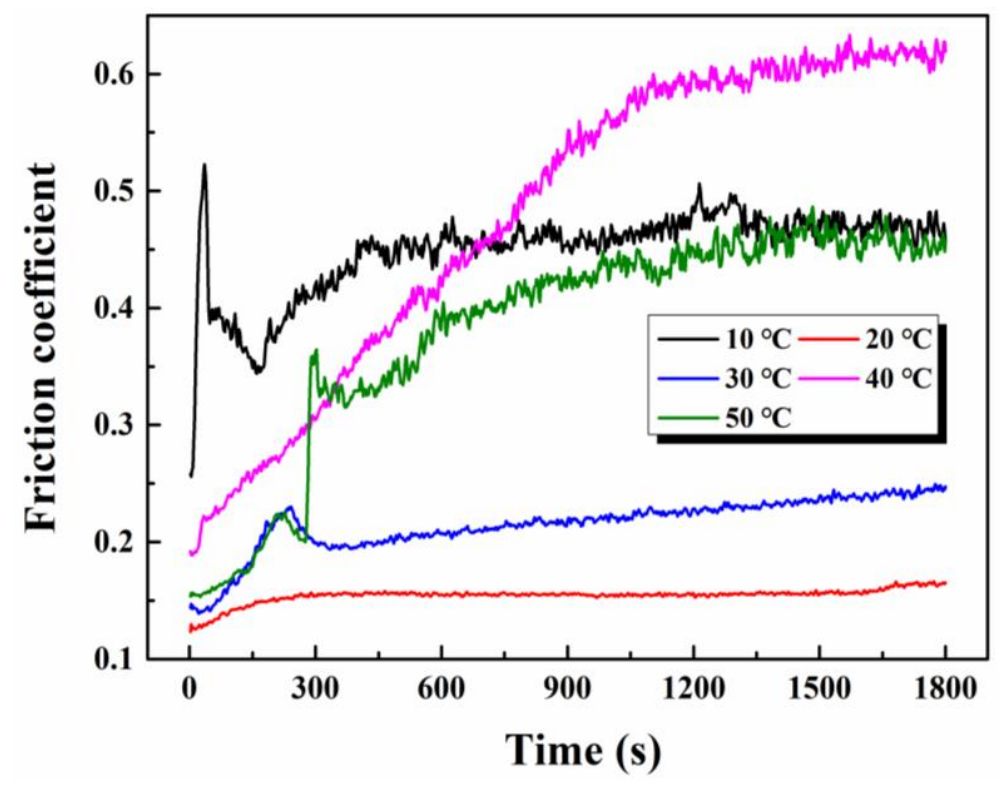

Figure 10. Friction coefficients of composite anodic films fabricated at different temperatures.

Cross-sections of wear tracks and wear rates of composite anodic films fabricated at different electrolyte temperatures are shown in Figure 11. Two figures display that the depth, width and wear rates of composite anodic films fabricated at $20^{\circ} \mathrm{C}$ and $30^{\circ} \mathrm{C}$ are much smaller than that of others. Moreover, the composite anodic films fabricated at $10{ }^{\circ} \mathrm{C}$ and $50{ }^{\circ} \mathrm{C}$ are worn out rapidly during the wear test. This is because the two kinds of films are too thin to be preserved and are removed by the counterpart continuously. As a result, the wear rates of composite anodic films fabricated at $10^{\circ} \mathrm{C}$ and $50{ }^{\circ} \mathrm{C}$ are as large as 95 and $54\left(10^{-6} \mathrm{~mm}^{3} \cdot \mathrm{N}^{-1} \cdot \mathrm{m}^{-1}\right)$, respectively. The wear rates of composite anodic films fabricated at 20,30 and $40^{\circ} \mathrm{C}$ are $1.2,1.6$ and $7.3\left(10^{-6} \mathrm{~mm}^{3} \cdot \mathrm{N}^{-1} \cdot \mathrm{m}^{-1}\right)$, respectively. These are smaller than that of the films fabricated at $10^{\circ} \mathrm{C}$ and $50^{\circ} \mathrm{C}$ by about two orders of magnitude. The sufficient amount of PTFE nanoparticles and the composite anodic films with sufficient thickness could provide adequate protection to prevent damage during the wear test. In addition, the composite anodic film fabricated at $20^{\circ} \mathrm{C}$ presents the lowest wear rate and this electrolyte temperature displayed 
the best synergistic effect of PTEF nanoparticles and anodic oxide film. Furthermore, the data of depth and width shown in Figure 11a also follow this rule.

(a)

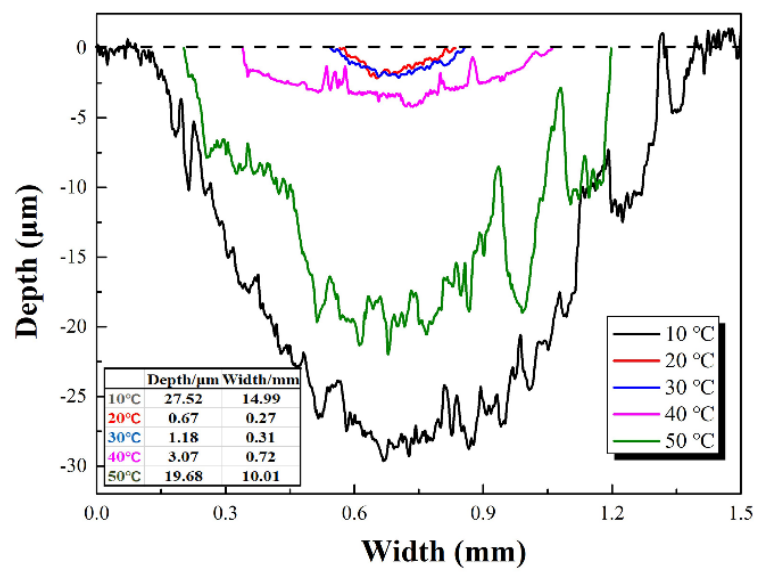

(b)

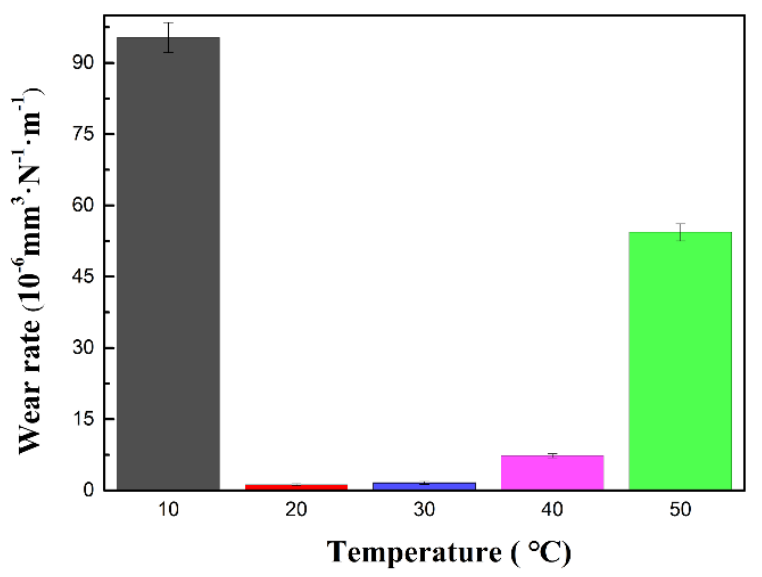

Figure 11. (a) Cross-section of wear tracks and (b) wear rates of composite anodic films fabricated at different temperatures.

Figure 12 displays the SEM and EDS images of the worn surface of composite anodic films fabricated at different electrolyte temperatures. Composite anodic films fabricated at anodizing electrolyte temperatures of $10{ }^{\circ} \mathrm{C}$ and $50^{\circ} \mathrm{C}$ (see Figure 12) produced wide deep worn surface furrows along the sliding direction, which are related to the higher friction coefficients and the larger wear rates. In addition, the sharp increase in the content of elemental Ti in Table 3 (1) and (5) indicate that the composite anodic films have been worn out. As shown in Figure 12b, lubrication regions appear on the contact areas due to mixed substrate and debris, which can explain the drop of friction coefficient in Figure 10. For the composite anodic film fabricated at $20^{\circ} \mathrm{C}$, a smooth lubricated surface consisting of softened PTFE nanoparticles and debris formed a lubricating layer as presented in Figure 12c,d. As a result, the narrowest and shallowest worn track is shown in Figure 12c. The EDS results in Tables 2 and 5 indicate that the content of PTFE nanoparticles first increases and then decreases with the increasing electrolyte temperature. Therefore, for the composite anodic film fabricated at $30^{\circ} \mathrm{C}$, the lubrication effect of its lubricating layer is worse than that of the film fabricated at $20{ }^{\circ} \mathrm{C}$, due to the reduction in the content of PTFE nanoparticles. Therefore, the second narrowest and shallowest worn surface exhibited on the composite anodic film. For the composite anodic film fabricated at $40^{\circ} \mathrm{C}$, the atomic percent of elemental $\mathrm{F}$ is $0.81 \%$, indicating that the content of PTFE nanoparticles is very small. In this case, PTFE nanoparticles have no synergistic effect with the anodic oxide film. As shown in Figure 12g, a relatively wide wear track appeared on the surface of the composite anodic film.

Table 5. The analysis results of corresponding EDS points in Figure 12.

\begin{tabular}{|c|c|c|c|c|c|}
\hline Elements & $\begin{array}{c}10{ }^{\circ} \mathrm{C}(\text { At. } \%) \\
\text { (1) }\end{array}$ & $\begin{array}{c}20{ }^{\circ} \mathrm{C}(\mathrm{At} . \%) \\
\text { (2) }\end{array}$ & $\begin{array}{c}30{ }^{\circ} \mathrm{C}(\mathrm{At} . \%) \\
\text { (3) }\end{array}$ & $\begin{array}{c}40{ }^{\circ} \mathrm{C}(\text { At. } \%) \\
\text { (4) }\end{array}$ & $\begin{array}{c}50{ }^{\circ} \mathrm{C} \text { (At.\%) } \\
\text { (5) }\end{array}$ \\
\hline $\mathrm{OK}$ & 7.93 & 36.11 & 54.14 & 65.73 & 10.05 \\
\hline F K & 0.04 & 18.34 & 12.26 & 0.21 & 0.09 \\
\hline $\mathrm{Al} \mathrm{K}$ & 3.62 & 0.38 & 1.20 & 1.34 & 5.30 \\
\hline Si K & 0.73 & 0.65 & 0.09 & 0.03 & 0.90 \\
\hline Ti K & 61.02 & 10.83 & 21.65 & 19.26 & 59.07 \\
\hline V K & 6.11 & 1.25 & 3.32 & 2.35 & 7.42 \\
\hline Fe K & 1.46 & 0.05 & 0.47 & 0.28 & 0.88 \\
\hline
\end{tabular}



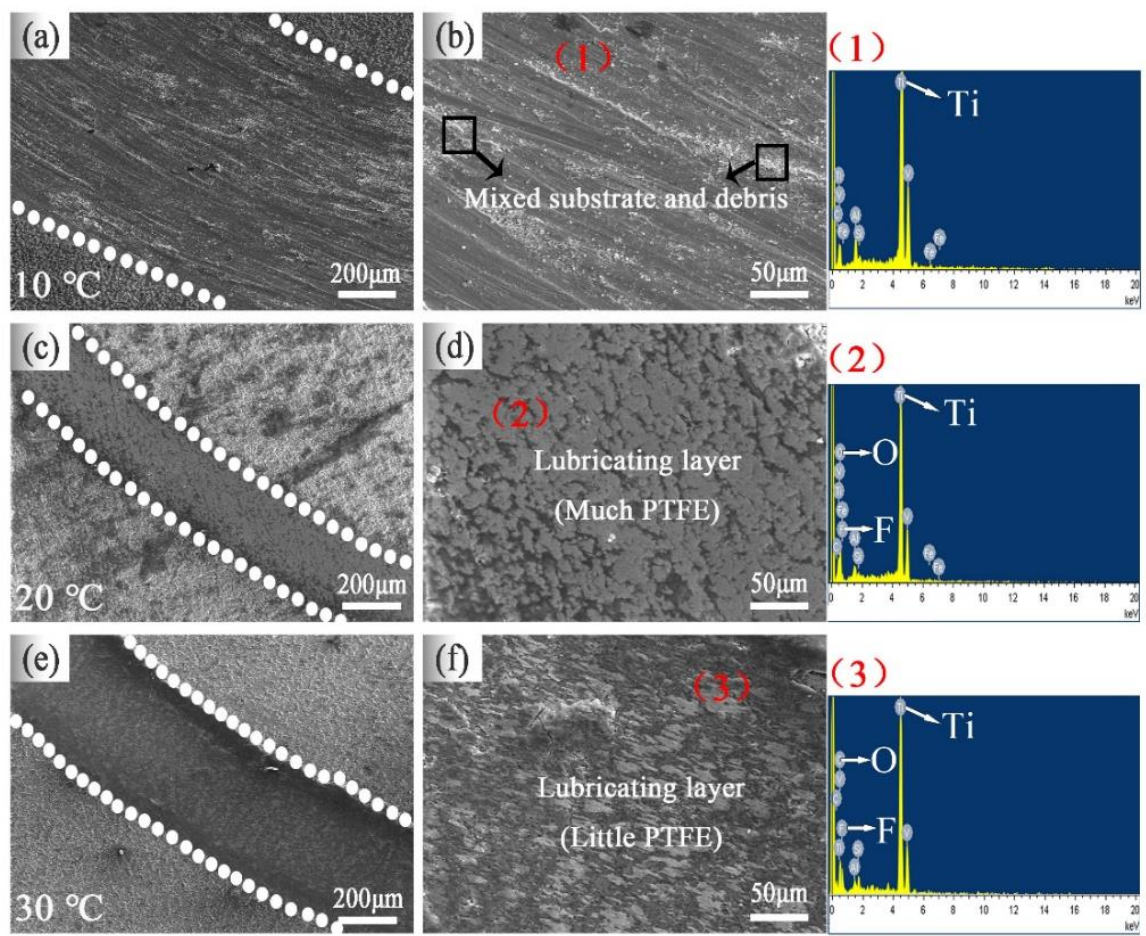

(3)
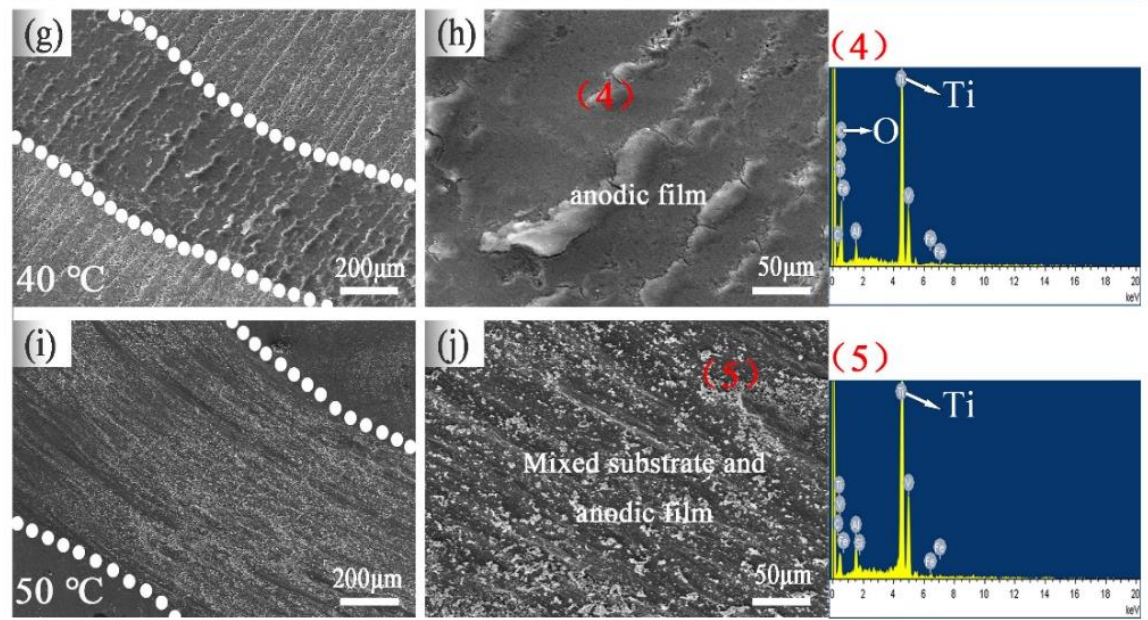

Figure 12. The SEM and EDS images of the worn surface for composite anodic films fabricated at different temperatures: (a,b) (1) $10{ }^{\circ} \mathrm{C}$; (c,d) (2) $20{ }^{\circ} \mathrm{C}$; (e,f) (3) $30{ }^{\circ} \mathrm{C}$; (g,h) (4) $40{ }^{\circ} \mathrm{C}$; (i,j) (5) $50{ }^{\circ} \mathrm{C}$.

\subsection{Lubrication Mechanism}

Figure 13 shows the corresponding lubrication mechanism of the composite anodic films fabricated at different electrolyte temperatures during the wear test. According to the data, the anodic films with higher PTFE nanoparticles exhibit better synergistic effects. In addition, the lubrication mechanism is proposed as follows. During the counterpart being rubbed against the sample, extrusion force and high electrolyte temperature both led the composite anodic films especially the PTFE inside to deform and bond together with detrital-matters. After that, a lubrication layer was formed gradually between the contact areas and thus the highest PTFE nanoparticles correspond to the best lubrication layer (see $20^{\circ} \mathrm{C}$ ), which determined the final tribological property of composite anodic films [20]. In Figure 13a, the films fabricated at $10^{\circ} \mathrm{C}$ and $50^{\circ} \mathrm{C}$, have the same final friction pattern in that their substrate was destroyed. However, in Figure 13b, the composite anodic films fabricated at $20^{\circ} \mathrm{C}$ and $30^{\circ} \mathrm{C}$ have not been worn out and their friction coefficients were very low (as shown in Figure 10). This is because there are a lot of PTFE nanoparticles on their surfaces, causing the deformed PTFE nanoparticles 
to bond together with detrital-matters and form the lubricating layer easily. The amount of PTFE nanoparticles in the composite anodic film fabricated at $20^{\circ} \mathrm{C}$ is more compared with the film fabricated at $30{ }^{\circ} \mathrm{C}$. The thickness and surface roughness of the composite anodic film fabricated at $20^{\circ} \mathrm{C}$ are also larger. All of these are favorable for forming a lubricating layer. This is also the reason why the friction coefficient of the composite anodic film fabricated at $20^{\circ} \mathrm{C}$ is smaller than that of the film fabricated at $30^{\circ} \mathrm{C}$. When the electrolyte temperature increases to $40^{\circ} \mathrm{C}$, the composite anodic film becomes thinner and fewer PTFE nanoparticles exist in the film, as shown in Figure 13c. Hence, it is difficult to form a lubricating layer and thus the friction coefficient increases gradually before the composite anodic film is worn out.
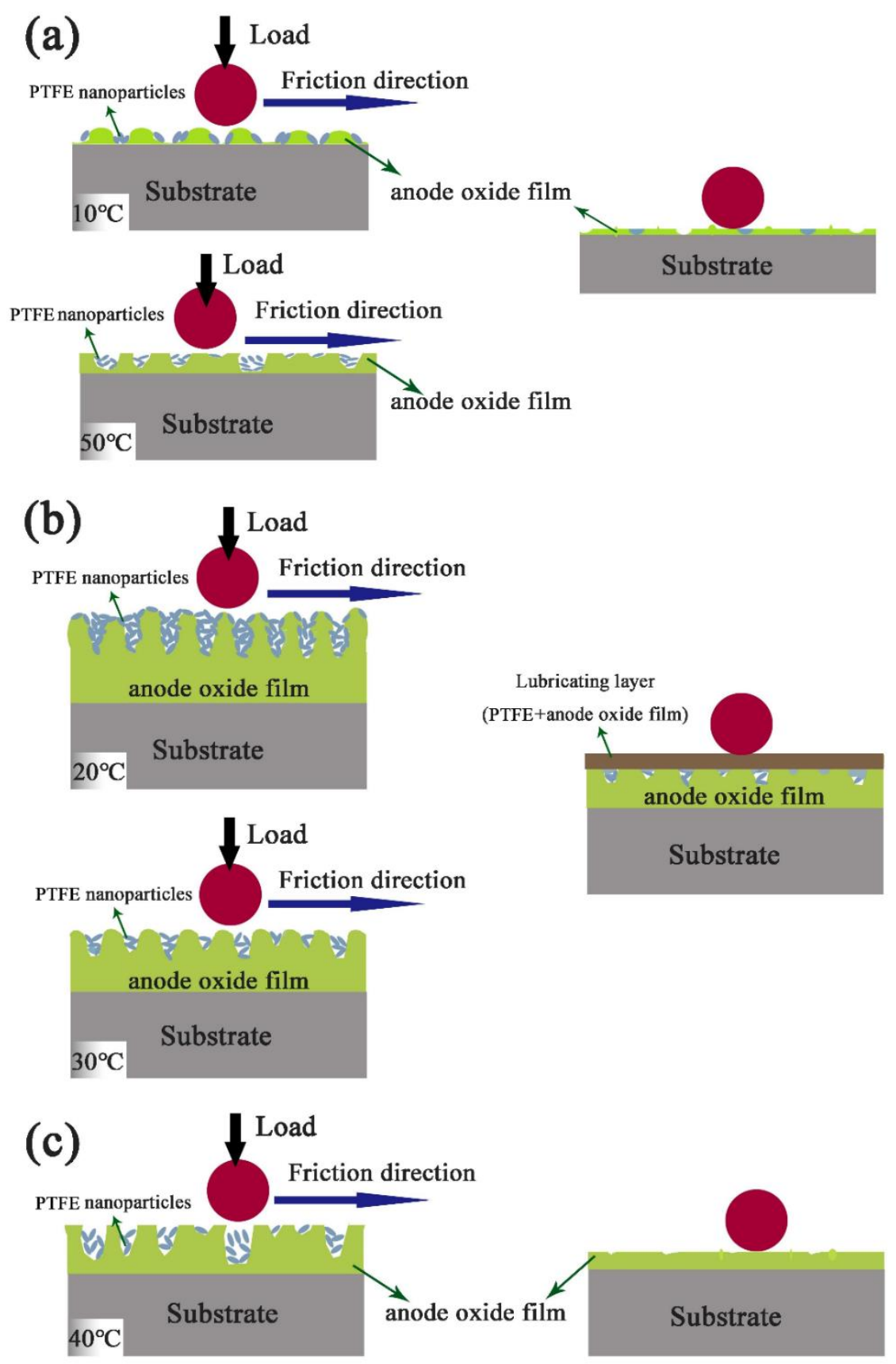

Figure 13. The corresponding lubrication mechanism of composite anodic films fabricated at different temperatures during the wear test. (a) $10^{\circ} \mathrm{C}$ and $50{ }^{\circ} \mathrm{C}$ (b) $20^{\circ} \mathrm{C}$ and $30^{\circ} \mathrm{C}$ (c) $40^{\circ} \mathrm{C}$. 
In a few words, the electrolyte temperature has a great effect on the tribological properties of composite anodic film. Moreover, the composite anodic film fabricated at $20^{\circ} \mathrm{C}$, has the lowest friction coefficient of about 0.14 and remains very stable during the wear test.

\section{Conclusions}

Composite anodic films were successfully fabricated on Ti-10V-2Fe-3Al alloy by a one step anodizing process in a new environmentally-friendly electrolyte containing malic acid and PTFE nanoparticles at different temperatures. The influences of electrolyte temperature on the morphology, structure, surface hydrophobicity, corrosion and wear resistance of the films were investigated. The conclusions were as follows:

(1) Electrolyte temperature, as a thermodynamic factor, affects the growth of the composite anodic films, resulting in its different surface roughness. As a result, PTFE nanoparticles are more easily adsorbed on rough surfaces of films, which causes a strong hydrophobicity $(\mathrm{CA}=131.95)$ at $20^{\circ} \mathrm{C}$.

(2) To a certain extent, the lower electrolyte temperature, the more crystalline oxides (anatase and rutile) can be obtained in the films. Under the constant current, the final voltage decreases with the electrolyte temperature. Higher final voltages do not always result in a thicker oxide film and the electrolyte temperature also has an obvious effect on the film thickness.

(3) The corrosion and wear resistance of the film increased with electrolyte temperature until it reached the maximum at $20^{\circ} \mathrm{C}$. It was attributed to the PTFE particles with hydrophobicity in pores providing a physical barrier against the immersion of $\mathrm{Cl}^{-}$, with the rest down to the formation of the PTFE lubricating layer.

Author Contributions: Conceptualization, Y.W. and L.W.; formal analysis, Y.W., X.D., L.L. and L.W.; funding acquisition, L.W.; investigation, Y.W., L.L., H.W., Y.L., and L.W.; project administration, L.W.; resources, L.W.; supervision, F.P. and L.W.; validation, Y.W., Z.-H.X., H.W. and L.W.; visualization, Y.W. and L.W.; writing-original draft, Y.W.; writing-review and editing, Y.W., G.Z., W.Y. and L.W. All authors have read and agreed to the published version of the manuscript.

Funding: This work was supported by the National Natural Science Foundation of China $(51971040,51701029)$, the Fundamental Research Funds for the Central Universities (2020CDJQY-A007), China Postdoctoral Science Foundation Funded Project (2017M620410, 2018T110942), the Chongqing Postdoctoral Scientific Research Foundation (Xm2017010).

Conflicts of Interest: No conflict of interest exits in the submission of this manuscript, and manuscript is approved by all authors for publication. I would like to declare on behalf of my co-authors that the work described was original research that has not been published previously, and not under consideration for publication elsewhere, in whole or in part.

\section{References}

1. Pal, S.; Peršin, Z.; Vuherer, T.; Drstvenšek, I. The Effect of Ti-6Al-4V Alloy Surface Structure on the Adhesion and Morphology of Unidirectional Freeze-Coated Gelatin. Coatings 2020, 10, 434. [CrossRef]

2. Ossowska, A.; Zieliński, A.; Olive, J.-M.; Wojtowicz, A. Influence of Two-Stage Anodization on Properties of the Oxide Coatings on the Ti-13Nb-13Zr Alloy. Coatings 2020, 10, 707. [CrossRef]

3. Gao, K.; Wang, Z.; Jia, Q.; Zhang, B.; Mou, Z. The Utilization of Carbon Dioxide to Prepare TiCxOy Films with Low Friction and High Anti-Corrosion Properties. Coatings 2020, 10, 533. [CrossRef]

4. Zimowski, F; Moskalewicz, K. The Influence of Electrophoretic Deposition Parameters and Heat Treatment on the Microstructure and Tribological Properties of Nanocomposite Si3N4/PEEK 708 Coatings on Titanium Alloy. Coatings 2019, 9, 530.

5. Ma, K.; Yu, M.; Liu, J.; Li, S.; Wu, L.; Yao, W. Effect of sodium tartrate concentrations on morphology and characteristics of anodic oxide film on titanium alloy Ti-10V-2Fe-3Al. Chin. J. Aeronaut 2016, 29, 1151-1158. [CrossRef]

6. Luz, A.R.; de Souza, G.B.; Lepienski, C.M.; Siqueira, C.J.M. Tribological properties of nanotubes grown on Ti-35Nb alloy by anodization. Thin Solid Film. 2018, 660, 529-537. [CrossRef] 
7. Mehdi, M.; Farokhzadeh, K.; Edrisy, A. Dry sliding wear behavior of superelastic Ti-10V-2Fe-3Al $\beta$-titanium alloy. Wear 2016, 350-351, 10-20. [CrossRef]

8. Ge, Y.; Xu, J.; Huan, H. Tool wear during high speed turning in situ TiCp/TiBw hybrid reinforced Ti-6Al-4V matrix composite. Chin. J. Aeronaut 2016, 29, 1425-1435. [CrossRef]

9. Wang, D.; Li, H.; Yang, H.; Ma, J.; Li, G. Tribological evaluation of surface modified H13 tool steel in warm forming of Ti-6Al-4V titanium alloy sheet. Chin. J. Aeronaut 2014, 27, 1002-1009. [CrossRef]

10. Wu, L.; Wen, C.; Zhang, G.; Liu, J. Influence of anodizing time on morphology, structure and tribological properties of compositeanodic films on titanium alloy. Vacuum 2017, 140, 176-184. [CrossRef]

11. Wang, S.; Liao, Z.; Liu, Y.; Liu, W. Different tribological behaviors of titanium alloys modified by thermal oxidation and spraying diamond like carbon. Sur. Coat. Technol. 2014, 252, 64-73. [CrossRef]

12. Koshuro, V.; Fomin, A.; Rodionov, I. Composition, structure and mechanical properties of metal oxide coatings produced on titanium using plasma spraying and modified by micro-arc oxidation. Ceram. Int. 2018, 44, 12593-12599. [CrossRef]

13. Zubillaga, O.; Cano, F.J.; Azkarate, I.; Molchan, I.S.; Thompson, G.E.; Skeldon, P. Anodic films containing polyaniline and nanoparticles for corrosion protection of AA2024T3 aluminium alloy. Sur. Coat. Technol. 2009, 203, 1494-1501. [CrossRef]

14. Escobar, J.; Arurault, L.; Turq, V. Improvement of the tribological behavior of PTFE-anodic film composites prepared on 1050 aluminum substrate. Appl. Surf. Sci. 2012, 258, 8199-8208. [CrossRef]

15. Mei, S.; Wang, H.; Wang, W.; Tong, L.; Pan, H.; Ruan, C.; Ma, Q.; Liu, M.; Yang, H.; Zhang, L.; et al. Antibacterial effects and biocompatibility of titanium surfaces with graded silver incorporation in titania nanotubes. Biomaterials 2014, 35, 4255-4265. [CrossRef] [PubMed]

16. Baszkiewicz, J.; Krupa, D.; Mizera, J. Corrosion resistance of the surface layers formed on titanium by plasma electrolytic oxidation and hydrothermal treatment. Vacuum 2005, 78, 143-147. [CrossRef]

17. Wang, X.; Li, L.; Xie, Z.-H.; Yu, G. Duplex coating combining layered double hydroxide and 8-quinolinol layers on Mg alloy for corrosion protection. Electrochim. Acta 2018, 283, 1845-1857. [CrossRef]

18. Wu, L.; Ding, X.; Zheng, Z.; Ma, Y.; Atrens, A.; Chen, X.; Xie, Z.; Sun, D.; Pan, F. Fabrication and characterization of an actively protective $\mathrm{Mg}-\mathrm{Al} \mathrm{LDHs} / \mathrm{Al} 2 \mathrm{O} 3$ composite coating on magnesium alloy AZ31. Appl. Surf. Sci. 2019, 487, 558-568. [CrossRef]

19. Li, S.-M.; Yu, X.-M. Microstructure and abrasive wear behaviour of anodizing composite films containing SiC nanoparticles on Ti6Al4V alloy. J. Cent South Univ. 2014, 21, 4415-4423. [CrossRef]

20. Li, S.; Zhu, M.; Liu, J.; Yu, M.; Wu, L.; Zhang, J.; Liang, H. Enhanced tribological behavior of anodic films containing SiC and PTFE nanoparticles on Ti6Al4V alloy. Appl. Surf. Sci. 2014, 316, 28-35. [CrossRef]

21. Aliofkhazraei, M.; Rouhaghdam, A.S.; Shahrabi, T. Abrasive wear behaviour of Si3N4/TiO2 nanocomposite coatings fabricated by plasma electrolytic oxidation. Sur. Coat. Technol. 2010, 205, S41-S46. [CrossRef]

22. Wu, H.; Zhu, L.-N.; Yue, W.; Fu, Z.-Q.; Kang, J.-J. Wear-resistant and hydrophobic characteristics of PTFE/CF composite coatings. Prog. Org. Coat 2019, 128, 90-98. [CrossRef]

23. Liu, Y.; Xu, N.; Wang, Y.; Yao, Y.; Xiao, H. Preparation and tribological properties of hybrid PTFE/Kevlar fabric self-lubricating composites. Sur. Coat. Technol. 2019, 361, 196-205. [CrossRef]

24. Arrabal, R.; Matykina, E.; Viejo, F.; Skeldon, P.; Thompson, G.E. AC plasma electrolytic oxidation of magnesium with zirconia nanoparticles. Appl. Surf. Sci. 2008, 254, 6937-6942. [CrossRef]

25. Oh, S.H.; Finones, R.R.; Daraio, C.; Chen, L.H.; Jin, S. Growth of nano-scale hydroxyapatite using chemically treated titanium oxide nanotubes. Biomaterials 2005, 26, 4938-4943. [CrossRef] [PubMed]

26. Yin, X.; Mu, P.; Wang, Q.; Li, J. Superhydrophobic ZIF-8 based dual-layer coating for enhanced corrosion protection of Mg alloy. ACS Appl. Mater. Interfaces 2020, 12, 35453-35463. [CrossRef]

27. Blawert, C.; Dietzel, W.; Ghali, E.; Song, G. Anodizing Treatments for Magnesium Alloys and Their Effect on Corrosion Resistance in Various Environments. Adv. Eng. Mater. 2006, 8, 511-533. [CrossRef]

28. Krasicka-Cydzik, E. Gel-like layer development during formation of thin anodic films on titanium in phosphoric acid solutions. Corros. Sci. 2004, 46, 2487-2502. [CrossRef]

29. Bharathiraja, B.; Selvakumari, I.A.E.; Jayamuthunagai, J.; Kumar, R.P.; Varjani, S.; Pandey, A.; Gnansounou, E. Biochemical conversion of biodiesel by-product into malic acid: A way towards sustainability. Sci. Total Environ. 2020, 709, 136206. [CrossRef] 
30. Wu, C.; Liu, Q.; Chen, R.; Liu, J.; Zhang, H. Fabrication of ZIF-8@SiO2 Micro/Nano Hierarchical Superhydrophobic Surface on AZ31 Magnesium Alloy with Impressive Corrosion Resistance and Abrasion Resistance. ACS Appl. Mater. Interfaces 2017, 9, 11106-11115. [CrossRef]

31. Li, S.; Yao, W.; Liu, J. Study on anodic oxidation process and property of composite film formed on Ti-10V-2Fe-3Al alloy in SiC nanoparticle suspension. Sur. Coat. Technol. 2015, 277, 234-241. [CrossRef]

32. Zheludkevich, M.L.; Tedim, J.; Ferreira, M.G.S. "Smart" coatings for active corrosion protection based on multi-functional micro and nanocontainers. Electrochim. Acta 2012, 82, 314-323. [CrossRef]

33. de Miera, M.S.; Curioni, M.; Skeldon, P.; Thompson, G.E. The behaviour of second phase particles during anodizing of aluminium alloys. Corros. Sci. 2010, 52, 2489-2497. [CrossRef]

34. Byeon, A.; Zhao, M.Q.; Ren, C.E.; Halim, J.; Kota, S.; Urbankowski, P.; Anasori, B.; Barsoum, M.W.; Gogotsi, Y. Two-Dimensional Titanium Carbide MXene as a Cathode Material for Hybrid Magnesium/Lithium-Ion Batteries. ACS Appl. Mater. Interfaces 2017, 9, 4296-4300. [CrossRef] [PubMed]

35. Xia, X.; Zhitomirsky, I.; McDermid, J.R. Electrodeposition of zinc and composite zinc-yttria stabilized zirconia coatings. J. Mater. Process. Technol. 2009, 209, 2632-2640. [CrossRef]

36. Liu, J.H.; Wu, G.L.; Yu, M.; Wu, L. Influence of incremental rate of anodising current on roughness and electrochemical corrosion of oxide film on titanium alloy Ti-10V-2Fe-3Al. Surf. Eng. 2013, 28, 406-411. [CrossRef]

37. Miyakita, N.; Tanigaki, N.; Morishige, T.; Takenaka, T. Effect of Voltage on Mg-Li-Al Alloy Anodic Oxide Film. Mater. Sci. Forum 2018, 941, 1194-1197. [CrossRef]

38. Li, C.; Wu, L.; Zhao, S.; Jiang, L.; Yang, Y.; Zhang, K.; Zhu, X. Essential influence of electrode and electrolyte temperatures on the anodizing process of Ti. Chem. Phys. Lett. 2019, 722, 6-11. [CrossRef]

39. Yan, H.; Li, W.; Li, H.; Fan, X.; Zhu, M. Ti3C2 MXene nanosheets toward high-performance corrosion inhibitor for epoxy coating. Prog. Org. Coat. 2019, 135, 156-167. [CrossRef]

40. Dong, G.Z.; Fan, H.Q.; Zhu, Y.N.; Pan, X.B.; Jiang, X.B. Effects of hyperthermia induced crystalline aggregation on properties of TiO2thin films. Surf. Eng. 2014, 30, 600-605. [CrossRef]

41. Wang, Y.; Dou, H.; Wang, J. Three-dimensional porous MXene/layered double hydroxide composite for high performance super capacitors. J. Power Sources 2016, 327, 221-228. [CrossRef]

42. Zhang, G.; Wu, L.; Tang, A. Growth behavior of MgAl-layered double hydroxide films by conversion of anodic films on magnesium alloy AZ31 and their corrosion protection. Appl. Surf. Sci. 2018, 456, 419-429. [CrossRef]

43. Zhang, G.; Wu, L.; Tang, A.; Ma, Y.; Song, G.-L.; Zheng, D.; Jiang, B.; Atrens, A.; Pan, F. Active corrosion protection by a smart coating based on a MgAl-layered double hydroxide on a cerium-modified plasma electrolytic oxidation coating on Mg alloy AZ31. Corros. Sci. 2018, 139, 370-382. [CrossRef]

Publisher's Note: MDPI stays neutral with regard to jurisdictional claims in published maps and institutional affiliations.

(C) 2020 by the authors. Licensee MDPI, Basel, Switzerland. This article is an open access article distributed under the terms and conditions of the Creative Commons Attribution (CC BY) license (http://creativecommons.org/licenses/by/4.0/). 